\title{
A CRIAÇÃO DE UNIDADES DE CONSERVAÇÃO EM ÁREAS DE APOSSAMENTO DE POPULAÇÕES TRADICIONAIS
}

UM PROBLEMA AGRÁRIO OU AMBIENTAL?

José Heder Benatti*

\section{Introdução}

A discussão que iremos apresentar neste trabalho faz parte de nosso projeto de pesquisa que desenvolvemos em parceria com entidades de base e organizações nãogovernamentais $(\mathrm{ONGs})^{1}$, com o intuito de apresentar uma proposta de regularização fundiária dos apossamentos das populacõoes tradicionais da Amazônia. As áreas com as quais desenvolveremos nosso trabalho são: Parque Nacional do Jaú - AM; comunidade de ribeirinhos da ilha de Ituqui, no município de Santarém - PA; comunidade de remanescentes do Quilombo de Pacoval, no município de Alenquer - PA. São diferentes áreas de pesquisa, uma está em uma unidade de conservação, outra, em uma ilha no rio Amazonas e a última é um quilombo em terras da União. Contudo, neste momento, pretendemos discutir somente um dos casos analisados, que é o das populações tradicionais em Unidades de Conservação (UC) de uso indireto ${ }^{2}$.

\footnotetext{
* Professor do Centro de Ciências Jurídicas da UFPA, mestre em Instituições Jurídicas e Sociais da Amazônia, pesquisador associado do Núcleo de Altos Estudos Amazônicos - NAEA/UFPA e coordenador do Programa de Políticas Públicas do Instituto de Pesquisa Ambiental da Amazônia - IPAM.

1 Este projeto, "Regularização fundiária em apossamento agroextrativista na Amazônia", é uma pesquisa do Instituto de Pesquisa Ambiental da Amazônia, financiada pela Fundação Ford e conta com o apoio institucional do Núcleo de Altos Estudos Amazônicos - NAEA/UFPA e do Departamento de Direito Civil, do CCJ/UFPA.

2 Agradecemos o convite e o apoio da Fundação Vitória Amazônica - FVA para participar da discussão do Plano de Manejo do Parque Nacional do Jaú, que foram fundamentais para que pudéssemos realizar nosso trabalho.
} 
Não resta dúvida da importância das áreas protegidas como uma das políticas públicas para a preservação dos recursos naturais. Neste contexto, o Brasil destaca-se no cenário internacional com cerca de 30\% das florestas tropicais existentes no mundo, possuindo uma alta diversidade e endemismo de espécies, o que coloca o país entre os que possuem maior biodiversidade.

O bioma amazônico, considerando suas florestas, rios, enclaves não florestais e ecótonos, possui uma extensão aproximada de $3.700 .00 \mathrm{~km}^{2}(74 \%$ da área da Amazônia Legal - 5.000.000 km²). Destes, 137.609,7 km² estão protegidos em 32 Unidades de Conservação federais de uso indireto ${ }^{3}$, que eqüivalem a $3,7 \%$ do bioma ${ }^{4}$.

O governo brasileiro está pretendendo expandir o número de áreas protegidas no país com a criação de novas Unidades de Conservação de uso indireto. Com esse objetivo, assumiu o compromisso de, até o ano 2000, estabelecer e efetivamente implementar na Amazônia novas áreas protegidas de uso indireto, abrangendo no mínimo $10 \%$ do bioma, o que significa um acréscimo ao existente de aproximadamente $270.100 \mathrm{~km}^{2}$.

Mas o problema é que boa parte das áreas protegidas criadas não foram efetivamente implantadas, não passam de "unidades de conservação no papel", pois a maioria das unidades de proteção integral apresentam problemas $(53,4 \%)$. Os principais problemas são: existência de terras ainda não completamente regularizadas, demarcadas, falta de equipamentos e de funcionários suficientes para fiscalizar e administrar a área; presença de populações humanas dentro das áreas protegidas; existência de planos de manejo e de gerenciamento em apenas poucas unidades. Em outras palavras, na atual situação das UC de uso indireto, o país não está conservando nem o $1,8 \%$ dos biomas brasileiros.

Dentro desse contexto, sobressai o conflito das populações humanas em áreas naturais protegidas integralmente. A existência das populações humanas tornou-se um tema central na questão das áreas protegidas no cenário nacional e internacional.

As populações humanas em UC são as populações tradicionais ${ }^{5}$ e as nãotradicionais. Estas são os fazendeiros, os veranistas, os comerciantes, os servidores públicos, os empresários, os empregados, os donos de empresas de beneficiamento de produtos extrativos, os madeireiros etc. Aquelas são os caboclos, os ribeirinhos, os caiçaras, os pescadores artesanais e os grupos extrativistas. Iremos analisar apenas o conflito com as populações tradicionais nas UCs de uso indireto.

3 As Unidades de Conservação de uso indireto são aquelas em que não é permitida nenhuma forma direta de utilização dos seus atributos naturais, elas estariam sob proteção integral, sendo admitido apenas o uso indireto dos seus recursos naturais. Nessa classificação incluem-se os Parques (nacionais, estaduais e naturais municipais), as Reservas Biológicas, as Estações Ecológicas, os Monumentos Naturais e os Refúgios da Vida Silvestre.

4 O Programa das Nações Unidas para o Meio Ambiente - PNUMA apresenta como proposta ideal de conservação uma superfície de $10 \%$ de cada bioma da Terra, a qual deveria ser transformada em área protegida. Atualmente cerca de $5 \%$ da superfície da Terra estão legalmente protegidos, contando com 7.000 unidades de conservação, federais, estaduais, municipais e também particulares, em 130 países (Kemf, 1993, apud Diegues, 1994, p. 13).

5 O Centro Nacional do Desenvolvimento Sustentado das Populações Tradicionais - CNPT, com sede em Brasília, criado pela Portaria n. ${ }^{\circ}$ 22/N/92, de 16 de fevereiro de 1992, define populações tradicionais como "todas as comunidades que tradicional e culturalmente têm sua subsistência baseada no extrativismo de bens naturais renováveis, um conceito flexivel para atender a diversidade de comunidades rurais existentes no Brasil” (Murrieta e Rueda, 1995, p. 51). 
O principal litígio jurídico existente deve-se ao fato de o atual conceito de UC de uso indireto excluir a presença humana dentro de sua área, inclusive as populações tradicionais.

\section{O direito das populações tradicionais às suas terras na ótica constitucional}

As definições de unidades de conservação contêm os princípios conservacionistas do início do século, com valores socioculturais largamente diferentes dos que iluminam a presente realidade brasileira, por isso exigem-se mudanças e adequações aos novos tempos, capazes de atualizá-los e fazer com que seus preceitos sejam aplicáveis ao abrigo de novos paradigmas.

$\mathrm{Na}$ elaboração das normas legais, o legislador, em maior ou menor grau, deixa-se impregnar pelos valores socioculturais vigentes naquele dado momento histórico. Logo, o espírito das leis espelha o espírito sociocultural vigente à época de sua elaboração.

Neste aspecto, a nossa Carta Magna de 1988 afirma categoricamente que "todos têm direito ao meio ambiente ecologicamente equilibrado, bem de uso comum do povo e essencial à sadia qualidade de vida, impondo-se ao Poder Público e à coletividade o dever de defendê-lo e preservá-lo para as presentes e futuras geraçôes" (caput do art. 225). Do mesmo modo, em outro artigo, afirma que "constituem patrimônio brasileiro os bens de natureza material e imaterial, tomados individualmente ou em conjunto, portadores de referência à identidade, à ação, à memória dos diferentes grupos formadores da sociedade brasileira, nos quais se incluem" tanto as formas de expressão como os modos de criar, fazer e viver (art. 216, incisos I e II).

Em nosso entendimento, a defesa do meio ambiente é muito mais do que a defesa somente da fauna, da flora e do meio físico, inclui também o ser humano, através de suas atividades culturais e materiais. Portanto, "o meio ambiente é $[. .$.$] a interação do conjunto de elementos$ naturais, artificiais e culturais que propiciem o desenvolvimento equilibrado da vida em todas as suas formas. $A$ interação busca assumir uma concep̧̧ão unitária do ambiente compreensiva dos recursos naturais $\boldsymbol{e}$ culturais"6 (grifos nossos).

Por isso, não seria demasiado lembrar que os princípios de criação das unidades de conservação, assim como os seus conceitos em vigor, são anteriores à Constituição atual, merecedores, portanto, de uma revisão a fim de que fiquem em sintonia com os mandamentos constitucionais. Caso contrário, estaríamos diante de uma inconstitucionalidade, pois temos, de um lado, uma Constituição que tutela os elementos naturais, artificiais e culturais, e, de outro, a lei ordinária ambiental que desconsidera o aspecto cultural.

Ao analisarmos o meio ambiente na ótica constitucional ${ }^{7}$, compreendemos que pelo menos três aspectos significativos merecem a proteção da Constituição Brasileira o natural, o artificial e o cultural.

O meio ambiente natural ou físico é "o conjunto de condiçoes, leis, influências e interações de ordem física, química e biológica, que permitem abrigar e reger a vida em todas as suas formas" (art. $3^{\circ}$, da

\footnotetext{
6 Silva, 1994, p. 2.

7 No nível internacional, temos a "Convenção Internacional Relativa à Proteção da Herança Universal Cultural e Natural”, aprovada em Paris no ano de 1972, da qual o Brasil é signatário. Seu principal objetivo é "estabelecer um sistema de proteção à herança cultural e natural de valor universal, organizando de forma permanente e de acordo com os modernos métodos cientificos".
} 
Lei 6.938/81). É constituído pelo solo, as águas, o ar atmosférico, os recursos biológicos ou qualquer outro componente dos ecossistemas.

O meio ambiente artificial engloba as construções, as edificações localizadas na área urbana - o chamados espaços urbanos fechados - e os bens públicos de uso comum do povo, tais como as praças, as ruas, as áreas verdes etc. - os chamados espaços urbanos abertos.

Podemos definir o meio ambiente cultural como "o patrimônio histórico, artístico, arqueológico, paisagístico, turístico, que, embora artificial, em regra, como obra do homem, difere do anterior (que também é cultural) pelo sentido de valor especial que adquiriu ou de que se impregnou's. Portanto, são os bens de natureza material ou imaterial, criados pelo ser humano, que podem ser tomados individual ou coletivamente, os quais fazem referência à identidade, à ação, à memória dos diferentes grupos formadores da sociedade brasileira.

A Constituição de 1988 deu muita importância à cultura, tomando esse termo no sentido mais abrangente, abarcando a noção de identidade e memória dos diferentes grupos formadores da sociedade brasileira. Tal noção é referida em vários artigos (23, III; 24, VII; 30, IX; 225; 261; especificamente quanto à etnia, art. 231). A preocupação com a questão cultural é tão marcante que se pode cogitar da existência de uma constituição cultural, ao lado de uma constituição política, econômica, social ou ambiental.

Dito isto, quando se cria uma área protegida, devem-se levar em consideração todos esses aspectos. Porém, a política governamental até agora desenvolvida considerou somente um ou alguns desses aspectos. Exemplificando, as unidades de conservação que possuem populações tradicionais poderiam fundamentar sua criação em pelo menos dois pontos que mereceriam proteção: o natural e o cultural. Mas, nas que foram criadas até hoje, o natural tem se sobreposto ao cultural; há casos em que, em nome da defesa do aspecto natural, destruiu-se, desarticulou-se o cultural, e isto ocorreu quando as populações tradicionais foram retiradas violenta e ilegalmente de suas áreas.

Essa política autoritária de criação de unidades de conservação em áreas de apossamento de populações tradicionais tem levado a uma colisão de dois direitos fundamentais garantidos constitucionalmente: o direito cultural e o natural (art. 215 e 225, respectivamente). Ocorre uma colisão de direitos fundamentais quando "o exercício de um direito fundamental por parte do seu titular colide com o exercício do direito fundamental por parte de outro titular. Aqui não estamos perante um cruzamento ou acumulação de direitos (como na concorrência de direitos), mas perante um 'choque', um autêntico conflito de direitos" $"$. Trata-se, portanto, de um conflito dos direitos fundamentais e bens jurídicos das populações tradicionais (patrimônio cultural) com o direito de preservação de um bem ambiental (patrimônio natural).

A tarefa de solucionar esses conflitos não é fácil, mas, de qualquer modo, devemos partir do pressuposto constitucional de que todos os direitos têm, em princípio, igual valor, devendo os seus conflitos solucionar-se, preferencialmente, mediante o recurso ao princípio da concordância prática, ou seja, a solução para o conflito não pode ser de uma forma que leve ao sacrifício (total) de um em relação ao outro. Os direitos constitucionais conflitantes são de igual valor constitucional, e não existe uma diferença hierárquica entre eles, portanto é

\footnotetext{
8 Silva, J. A. op cit, p. 3.

9 Canotilho, p. 495.
} 
importante chegar a uma solução que estabeleça limites e condicionantes recíprocos de forma a conseguir uma concordância prática entre os direitos ${ }^{10}$.

Se as unidades de conservação possuem entre seus princípios a preocupação de proteger os ecossistemas e espécies ameaçadas de extinção, a definição de ecossistemas que possibilitem a preservação da biodiversidade e a manutenção das funções biológicas essenciais ao equilíbrio do planeta. Por outro lado, as populações tradicionais representam etnias, grupos sociais que construíram sua territorialidade em um meio ambiente específico, por isso é um pressuposto condicional levar em consideração a forma peculiar de apossamento da terra dessas populações, assim como sua forma especial de utilizar os recursos naturais; assegurando, deste modo, o seu modo de fazer e viver em comunidade e a sua identidade cultural.

Entendemos que a área protegida é um importante instrumento para a política de conservação do meio ambiente brasileiro, mas a sua criação não pode restringir-se às informações do meio físico, portanto ficando a sua criação à mercê somente dos pareceres técnicos contidos nas ciências naturais, desconsiderando os processos sociais, econômicos, agrários e culturais existentes na área a ser protegida. O meio ambiente é uma concepção unitária, um todo composto por recursos naturais, artificiais e culturais.

\section{As populações tradicionais como destinatárias de um fim público}

Uma definição mais precisa da natureza jurídica das unidades de conservação implicaria classificá-las como bens ambientais de interesse público, devido ao próprio interesse ecológico e social que fundamenta a sua criação.

Logo, a destinação e a utilização da área não podem entrar em contradição com a finalidade do ato que criou a unidade, assim como seria uma ilegalidade, ou um erro de compreensão, afirmar que, ao se criar uma área protegida que contém população tradicional, essa área passaria a pertencer a esse grupo social. O objetivo da criação de uma unidade de conservação é proteger as suas características ambientais e culturais. A população tradicional precisa estar conjugada com o meio físico, o que dá base para a defesa dos atributos naturais e culturais tutelados pelo Poder Público. $O$ ato instituidor da área protegida não leva simplesmente em conta a população tradicional, pois um tratamento legal desigual estaria sendo dado em relação aos demais cidadãos brasileiros e grupos sociais, o que caracterizaria uma inconstitucionalidade, pois todos somos iguais perante a lei, sem distinção de qualquer natureza.

Dentro desse quadro, a concessão (e não a doação ou a venda) de uma área pública para as populações tradicionais parte do princípio de que a população beneficiada é "destinatária de um 'múnus público', decorrente de seu background e 'modus vivendi', que a capacita para cumprir a finalidade da lei. Este é o supedâneo jurídico da dispensa de concorrência pública prévia, prevista nos art. 15, $\int 1^{\circ}$ do Decreto-Lei $n^{\circ} 2.300 / 8711$, exigivel em todos os contratos firmados pelo Poder Público" 12 .

\footnotetext{
10 Idem, p. 163.

${ }^{11}$ Decreto-Lei no 2.300/86, art. 15, \1 1: “A Administração, preferencialmente à venda ou doação de bens imóveis, concederá direito real de uso, mediante concorrência. A concorrểncia poderá ser dispensada quando o uso destinar a concessionário de
} 
No momento em que o Poder Público reconhece o direito da população tradicional à sua terra, dentro de uma área protegida, está afirmando também que aquele grupo social tem uma finalidade de relevante interesse público a cumprir, finalidade essa que estará inscrita no ato de criação da unidade, em contratos que se estabelecerão entre o órgão público e a população beneficiada, nos quais constarão as formas de uso e manejo dos recursos naturais, que não poderão contrariar os objetivos do ato que criou a área ambiental.

\section{A previsão legal de ceder às populações tradicionais áreas da Unidade de Conservação}

A primeira dúvida que paira é saber da possibilidade jurídica da utilização de um bem ambiental de interesse público ou de um bem público por pessoas ou entidades privadas. Em outras palavras, podem as populações tradicionais utilizar as áreas de domínio público? $\mathrm{O}$ jurista especialista em Direito Administrativo, Diogenes Gasparini, afirma que esses bens "podem ser utilizados de modo especial por qualquer pessoa. Essa é a orientação, desde que a utilização satisfaça a um interesse público, não desvirtue a destinação, não importe a alienação e sejam atendidos, previamente, os requisitos legais.(...) $O$ uso privativo não transfere a propriedade do bem, mesmo que prolongado. Aliás é a própria Constituição Federal que ressalva essa possibilidade no $\int 3^{\circ}$ e $\int$ único dos arts. 183 e 191, respectivamente. O dominio, portanto, continua a pertencer ao Poder Público"13.

Uma das previsões administrativas para o uso dos bens públicos, e para este caso é o mais adequado, é o contrato de concessão de direito real de uso. Dissemos que é o mais conveniente para as partes porque oferece mais estabilidade na relação. Por se tratar de um direito real, ele se afirma, se fortalece pelo exercício, pela utilização do bem, desde que essa utilização respeite o que for acordado entre as partes contratantes.

A previsão legal do contrato de concessão de direito real de uso está no Decreto-Lei $n^{\circ}$ 271, de 28 de fevereiro de 1967, o qual estabelece que a concessão do direito real de uso de terreno é o contrato solene, pelo qual se transfere, a título de direito real, o usufruto temporário, por prazo certo ou indeterminado, de terreno público ou particular, para fins específico de urbanização, industrialização, edificação, cultivo da terra ou outra utilização de interesse social.

De modo geral, o domínio da unidade de conservação será do Poder Público e a transferência do usufruto para os moradores da unidade de conservação far-se-ápelo contrato de concessão de direito real de uso. Enquanto estiverem assegurados os interesses ambientais da sociedade, estarão também assegurados os direitos dos grupos sociais que utilizam essas áreas de forma não predatória. Portanto, enquanto existir o uso adequado da área, segundo o contrato, subsiste o direito real a essa utilização, podendo ser transferido esse direito para os herdeiros. Mas, no momento em que as populações não respeitarem o uso acordado ou

serviço público, a entidades assistenciais, ou verificar relevante interesse público na concessão, devidamente justificado.” (grifo nosso).

${ }^{12}$ Gomes e Felipe, 1994, p. 79.

${ }^{13}$ Gasparini, 1993, p. 530. 
mudarem a finalidade prevista legalmente, rescindir-se-á o contrato e a terra reverterá à Administração Pública.

Porém, se o motivo de findar a concessão não for por descumprimento contratual, mas por interesse das partes, as pessoas que receberam a concessão têm o direito de serem indenizadas pelas benfeitorias e trabalhos realizados no bem, como qualquer relação possessória.

O Contrato de Concessão incluirá o Plano de Utilização ${ }^{14}$ aprovado pelo órgão gestor da unidade e conterá cláusulas de rescisão quando houver quaisquer danos ao meio ambiente.

Caberá ao órgão gestor supervisionar as áreas agroextrativistas e acompanhar o cumprimento das condições estipuladas no Contrato de Concessão e no Plano de Utilização.

Para regularizar a situação fundiária da unidade, o contrato de concessão de direito real de uso poderá ser assinado por uma associação dos moradores da área protegida, legalmente constituída, que representará todos os moradores da unidade, portanto o contrato será coletivo, ou poder-se-ão realizar contratos individuais com cada família, desde que todas as famílias aprovem um único Plano de Utilização.

\section{As terras de apossamento das populações tradicionais}

Com base nas informações colhidas no trabalho de campo em nossa pesquisa ${ }^{15}$, podemos afirmar que as populações tradicionais formam o que podemos denominar de pequenos produtores rurais de base familiar, tendo sua economia familiar fundamentada no agroextrativismo. $\mathrm{Na}$ ótica fundiária são posseiros, pois ocupam terras sem consentimento de terceiro, conseqüentemente, não possuem títulos legais que lhes garantam o domínio da terra de que estão de posse, os únicos "títulos" que têm é o trabalho que realizam na terra para dar sustento a si e a suas famílias.

Para melhor compreensão do apossamento desses moradores das UC, apresentaremos três classificações jurídicas possíveis, sendo que a última classificação é a que melhor se enquadra no caso ora estudado.

\subsection{A visão civilista}

O Código Civil Brasileiro não definiu posse, mas sim o possuidor. Em seu texto legal, encontramos a definição no art. 458, em que se lê: "considera-se possuidor todo aquele que tem de fato

\footnotetext{
${ }^{14} \mathrm{O}$ Plano de Utilização nada mais é do que um documento escrito, proposto e elaborado pelos moradores da área protegida, a partir de seus conhecimentos acumulados historicamente, através da convivência com a natureza e do desenvolvimento de formas não predatórias de utilização dos recursos naturais, que garantem a conservação da floresta.

${ }^{15}$ Com o intuito de realizar o Plano de Manejo e o Levantamento Fundiário do PNJ, a Fundação Vitória Amazônica realizou em 1996 o recadastramento de todos os moradores do Parque. O primeiro levantamento ocorreu em 1988, realizado pelo Instituto de Terras e Colonização do Amazonas (ITERAM), e foram cadastradas somente 99 famílias. Foi um levantamento parcial, que não conseguiu cadastrar todas as famílias existentes no Parque naquele momento. O segundo levantamento foi realizado em 1992 pela Fundação Vitória Amazônica (Os moradores do Parque Nacional do Jaú: censo e levantamento sócio-econômico, março/1994), no qual foram registrados 1030 moradores, representando 156 famílias.
} 
o exercício, pleno ou não, de algum dos poderes inerentes ao dominio, ou propriedade". Na concepção civilista, a posse é a exteriorização da propriedade, advém de um direito, de um título.

Os efeitos produzidos pela posse estão normatizados nos artigos 499 a 519 e 522 do Código Civil. São eles: a percepção dos frutos, a responsabilidade pelas deteriorações, o direito a indenizações e retenção das benfeitorias, o usucapião e a reivindicação da posse pelos interditos possessórios.

Os dois principais efeitos a serem considerados são a indenização e a retenção de benfeitorias, que são tratados nos artigos 516 e 519 do Código Civil. Ou seja, o posseiro tem o direito de ser indenizado pelas benfeitorias encontradas em sua área, no caso de haver uma intervenção do Poder Público no seu imóvel rural.

\subsection{A visão agrarista}

Um dos princípios fundamentais do Direito Agrário é o reconhecimento do trabalho do homem (ou da mulher) na terra, ou seja, a posse agrária. A função social e econômica da posse agrária se dá através da vinculação à terra, desenvolvida por meio da atividade agrária. Por isso, "(...) o Direito Agrário elege como valor maior a atividade agrária (o trabalho) que o homem empreende na terra. V aloriza-a mais que o simples dominio. Desta maneira, o Direito Agrário orienta-se no sentido de reconhecer a posse àquele que, no plano dos fatos, labuta a terra, explorando-a economicamente"16.

A atividade agrária pode ser classificada como sendo "a ação do ruricola - que se cumpre através de um processo agrobiológico - sobre o conjunto de bens que integram a exploração rural a que se dedica profissionalmente, com o fito de lucro e para suprir as necessidades do ser bumano"17. Portanto, é o conjunto de bens e ações que integram a exploração racional da área rural a que se dedica o posseiro.

A finalidade da atividade agrária é justamente dar uma determinada destinação à terra, "quer tornando-a mercancia, onde já há o intuito de lucro, quer lhe retirando tal caráter, com o intuito meramente alimentar ou de satisfação de outras necessidades, quer resguardando-a a uma premência conservacionista, quer atentando-a num interesse cientifico, propriamente dito"18.

Destarte, não basta que ocorra a exploração de uma área rural, é importante que essa exploração se dê em bases que respeitem o meio ambiente, em sintonia com a legislação agroambiental.

Na posse agrária, o posseiro pode ser qualquer pessoa física ou jurídica que esteja apta, ou seja capaz de direitos e obrigações. O importante é que o agente seja capaz e, sendo pessoa física, não há diferenciação de tratamento entre homem e mulher.

No Direito Agrário brasileiro, a posse agrária tem como requisitos necessários a cultura efetiva e a morada habitual. A cultura efetiva é caracterizada quando o possuidor trabalha em uma área e dela tira os frutos para si e sua família, explorando-a economicamente com a devida preservação do meio ambiente. Já a morada habitual na terra é o local onde o posseiro costumeiramente pode ser encontrado trabalhando, com ânimo definitivo de desenvolver sua

\footnotetext{
${ }^{16}$ Mattos Neto, 1998, p. 45.

${ }^{17}$ Sodero, 1978, p. 406.

${ }^{18}$ Laranjeira, 1988, p. 68.
} 
atividade agrária, o que não obrigatoriamente significa que ele possui o seu domicílio nessa área.

Os efeitos da posse agrária são os mesmos da posse civil.

\subsection{A visão agroambiental}

As populações tradicionais possuem um apossamento da terra muito peculiar, que as legislações civilistas e agraristas não conseguem abarcar em sua plenitude. Diante dessa realidade específica, é necessário fazer uma leitura jurídica que consiga representar as posses desses segmentos de camponês.

A visão ainda existente sobre posse pode reduzi-la espacialmente a um "quadrilátero", só que essa compreensão não considera a totalidade das relações jurídicas e sociais que se desenvolvem na Amazônia. É necessário observar que, além da concepção jurídica formal, existem as concepções jurídicas de segmentos de camponeses, que historicamente formaram a posse agroecológica ${ }^{19}$.

Mesmo tratando-se de um único instituto jurídico - a posse - suas modalidades foram sendo constituídas em momentos históricos diferentes, com vários aspectos econômicos, jurídicos, sociais e ambientais bem particulares.

Para que se configure a posse civil há necessidade do elemento subjetivo. É preciso também que o possuidor tenha o título do bem. Já a posse agrária completa-se apenas com o fato objetivo da exploração da terra pelo possuidor. Na posse agroecológica, o fato objetivo é o uso sustentável da terra, pois para "ter" posse é preciso interagir com o meio.

É interessante notar que a terra, para esses segmentos de camponeses, não tem um caráter mercantil, não constitui objeto de troca, assim como não é vista como um bem sujeito a apossamento individual, mas somente na forma familiar conjugada com a coletiva.

Essa forma coletiva de apossamento dos recursos naturais e a presença de práticas de trabalho familiar com base no agroextrativismo são características da posse agroecológica.

A delimitação dos direitos dos camponeses sobre áreas que são utilizadas para o cultivo e a moradia familiar, enquanto outras porções de terra são reservadas para uso comum (onde se pratica o extrativismo), ocorre dentro de uma lógica espacial segundo a qual não há a necessidade de que essas áreas (uso comum e familiar) sejam adjacentes e permanentes. Nem mesmo que suas atividades laborais e de moradia estejam confinadas em parcelas fixas. Além disso, a distribuição dos roçados, casas e a área de uso comum, segundo uma certa divisão espacial da área, ocorre baseada num consenso do grupo, e não em ações isoladas.

Dentro dessa realidade, existem duas modalidades de apossamentos: o da comunidade, que é de uso coletivo, no qual se manifesta o sistema de uso comum da terra, e o apossamento familiar, apoiado na unidade de trabalho familiar (que pode ser entendido como "privado").

O sistema de uso comum na estrutura agrária brasileira sempre foi marginalizado, tanto que não temos um conceito de áreas de uso comum juridicamente consolidado, embora essas

\footnotetext{
${ }^{19}$ Para maiores informações sobre posse agroecológica, ver Benatti e Maués, 1994 e Benatti, 1997.
} 
áreas sejam consideradas "vitais para a sobrevivencia do conjunto das unidades familiares", que delas se utilizam ${ }^{20}$.

A dificuldade em definir áreas de uso comum, também conhecidas como terras comuns, está no fato de o controle dos recursos básicos não ser exercido livre e individualmente por uma família ou por um grupo doméstico de trabalhadores rurais, e as normas que regulam essa relação social vão além das normas jurídicas codificadas pelo Estado. $\mathrm{Na}$ realidade, essas áreas são reguladas por um conjunto de noções que tem o objetivo de disciplinar as relações com a terra e os demais recursos naturais.

Área de uso comum é "um bem não sujeito à apropriação individual em caráter permanente. Nestes espaços combinam-se as noções de propriedade privada e de apossamento de uso comum, onde encontra-se um grau de solidariedade e coesão social, formadas a partir de normas de caráter consensuais que garantem a manutenção destes espaços" 21 . São áreas cujos recursos são abertos, inalienáveis e indivisíveis. O acesso à terra para o exercício de atividades estritamente familiares, em parcelas da área de uso comum, só é permitido pelo conjunto de moradores para fazer casa, roça ou extrativismo, mas não para apropriar-se da área de uso comum em si.

Logo, área de uso comum são os rios, lagos, varadouros (caminhos reais), praias, barrancos e matas administradas pelo conjunto de moradores da área, onde se desenvolve o usufruto coletivo. São áreas abertas, não são de domínio privado e nem estão disponíveis à apropriação individual, mas esses "espaços abertos" estão vinculados ao mercado, pois seus produtos são vendidos e comercializados nas comunidades próximas.

A posse agroecológica é, fisicamente, a somatória dos espaços familiares e das áreas de uso comum da terra.

A posse agroecológica materializa-se, enquanto espaço ecológico e social, em três conjuntos: casa, roça e mata.

Entendemos como casa o espaço físico familiar que é utilizado como moradia, onde também se realizam as atividades domésticas, incluindo as áreas circundantes, que são a horta, o sítio (local onde se desenvolvem as culturas permanentes e se plantam as árvores frutíferas) e os espaços destinados à preparação da farinha (casa de farinha) e à criação de animais domésticos de pequeno porte. Em alguns casos, a casa de farinha desempenha mais a função de espaço social, pois é utilizada por mais de uma família e como local de reunião.

A roça: é o espaço físico familiar onde se desenvolvem as atividades produtivas agrícolas, que na maioria das vezes são de subsistência e que se distinguem da produção extrativista.

Os espaços considerados de apropriação familiar são aqueles relacionados ao produto do trabalho, como é o caso da casa, da roça e da capoeira. São espaços identificados com uma determinada família, fruto pleno de seu trabalho.

A mata é o espaço físico onde se encontram as árvores silvestres, a floresta, a fauna. $\mathrm{Na}$ mata desenvolvem-se as atividades extrativistas, como a coleta de frutos, castanhas, cipós, madeiras e a exploração do látex. Na mata, pratica-se a caça de subsistência.

\footnotetext{
${ }^{20}$ Almeida, 1989, p. 185.

${ }^{21}$ Almeida, op. cit., p. 183.
} 
$\mathrm{Na}$ mata, ou floresta, encontramos também as áreas de pousio (ou capoeira), que são espaços abertos anualmente na floresta para semear ou plantar por um ou dois anos. Em seguida, essas áreas são deixadas em repouso durante um período que pode ser longo o suficiente para que a floresta as invada novamente, possibilitando a recuperação dos nutrientes do solo. Eventualmente, na capoeira, ainda existe algum produto que pode ser colhido. $\mathrm{Na}$ maioria dos casos, é a mandioca.

Nesse conjunto de proposições foram apresentadas as diferenças com os padrões do direito estatal brasileiro, inclusive questionando o modelo tradicional de assentamento em lotes agrícolas padronizados, sem consideração da especificidade e diversidade do meio natural amazônico, e propondo a utilização coletiva da terra.

Destacamos ainda que a junção entre a questão fundiária e a posse agroecológica propõe novos critérios de apossamento da terra, centrados no uso sustentável dos recursos naturais; conseqüentemente, tem-se uma leitura diferenciada de morada habitual, cultura efetiva, benfeitoria e módulo rural.

As áreas ocupadas por esses segmentos de camponeses são os espaços onde se localizam as casas e as roças, além dos espaços utilizados para caça, pesca e as atividades de extrativismo vegetal. Logo, a noção de área apossada corresponde às terras utilizadas para garantir a reprodução característica do modo de vida desses camponeses.

Os efeitos jurídicos da posse agroecológica são os mesmos da posse civil e da posse agrária.

Portanto, qualquer perspectiva de resolução da questão fundiária das populações tradicionais em áreas protegidas deve levar em consideração a forma peculiar de apossamento desse segmento de camponês.

\section{Conclusão}

Temos clareza da importância das áreas protegidas no Brasil, assim como da necessidade de se buscar uma proposta mediadora para solucionar as injustiças que sofreram as populações tradicionais diretamente atingidas com a criação das Unidades de Conservação de uso indireto. Reconhecemos que a expulsão pura e simples das populações tradicionais de suas áreas, onde ocorreu o intrusamento com as áreas protegidas, é negativa tanto sob o aspecto social e agrário e traz sérias seqüelas para a natureza. distintos:

Por isso, é importante dividir a questão das populações tradicionais em dois momentos

a) Uma coisa é discutir os direitos das populações tradicionais nas unidades de proteção integral criadas antes de 1988, pois essas áreas foram criadas e geridas sem qualquer consulta à sociedade e nem levaram em consideração os direitos das comunidades mais diretamente atingidas.

Para esses casos, o Poder Público deverá buscar soluções que levem em consideração os direitos constitucionais ambientais, culturais e agrários. A decisão do Poder Público não poderá ser unilateral, mas deverá ser tomada com a participação das partes interessadas, ou seja, com a participação de representantes das populações tradicionais residentes nas unidades de conservação, do órgão gestor da unidade e, quando for o caso, de outras instituições 
públicas e privadas com reconhecida atuação na área, que deverão ter a incumbência de estudar e propor as medidas necessárias para superar o atual impasse.

b) A criação de novas Unidades de Conservação deverá ser precedida de estudos técnicos e de uma ampla consulta à população local, a residente na área e no entorno da unidade proposta, aos órgãos de governo da esfera federal, estadual e municipal, a instituições de pesquisa e a organizações não-governamentais. Essa consulta deverá ocorrer através de audiências públicas, reuniões locais com os diferentes setores da sociedade envolvidos diretamente com a área escolhida, sendo o órgão público ambiental obrigado a fornecer informações adequadas e inteligíveis à população local e às outras partes interessadas, dando-lhes tempo suficiente para que possam contribuir com suas próprias propostas. Ressalte-se que todo esse processo de discussão ajudará também a definir melhor a dimensão e os limites mais adequados para a área protegida.

Conseqüentemente, a criação de uma nova unidade de conservação vem precedida de debates, esclarecimentos sobre a importância da área protegida, e, durante essa discussão, vai se construindo a legitimidade da mesma na região, pois a deliberação final de criação - o tipo de unidade mais adequada, a dimensão e os limites - será uma decisão coletiva, em última instância, da sociedade.

Não podemos deixar de concluir que a pura e simples retirada das populações tradicionais de suas áreas representa uma violação dos princípios constitucionais, principalmente aqueles referentes ao respeito à cultura, ao meio ambiente e ao direito agrário. Portanto, é um problema tanto agrário como ambiental, um problema sócio-ambiental.

\section{Referências bibliográficas}

AGUIAR, Roberto A. R. de. Direito do meio ambiente e participação popular. Brasília, IBAMA, 1994.

ALMEIDA, Alfredo Wagner Berno de. Terras de preto, terras de santo, terras de índio - uso comum e conflitos. In: CASTRO, E. M. \& HEBETTE, J. (Org.) Na trilha dos Grandes Projetos. Belém, NAEA/UFPA, 1989.

ALVARENGA, Octavio Mello. Direito agrário e meio ambiente na Constituição de 1988. Forense, Rio de Janeiro, 1992.

ANTUNES, Paulo de Bessa. Curso de Direito Ambiental: doutrina, legislação e jurisprudência. Rio de Janeiro, Renovar, 1990. . Jurisprudência ambiental brasileira. Rio de Janeiro, Lumen Juris. 1995.

BENATTT, José Heder. Manual do plano de utilização para as reservas extrativistas. Brasília, CNPT/IBAMA, (Mimeo), 1993.

BENATTI, José Heder. "Posse Coletiva da Terra: um estudo jurídico sobre o apossamento de seringueiros e quilombolas". Revista CEJ/Conselho da Justiça Federal, Centro de Estudos Judiciários - vol. 1, n. ${ }^{\circ}$ 1, Brasília: CJF, 1997.

BENATTI, José Heder \& MAUÉS, Antonio Gomes Moreira. O pluralismo jurídico e as posses agrárias na Amazônia. In: Lições de Direito Civil Alternativo. São Paulo, Ed. Acadêmica, 1994. 
A posse agrária alternativa e a reserva extrativista. In: D’Incao, Maria Angela e Silveira, Isolda Maciel da (Coord). A Amazônia e a crise de moderniz̧ação. Belém, Museu Paraense Emílio Goeldi, 1994.

BRASIL. CONSTITUIÇÃO DA REPÚBLICA FEDERATIVA DO BRASIL. Brasília, Senado Federal, Centro Gráfico, 1988.

CÂMARA DOS DEPUTADOS. Estratégia mundial para a conservação. comissão de defesa dos consumidor, meio ambiente e minorias. Brasília, (Mimeo), set/1994.

Substitutivo ao Projeto de Lei $n^{\circ}$ 2.892/92. Comissão de defesa, do consumidor, meio ambiente e minorias. Brasília, (Mimeo), 1996.

DIEGUES, Antonio Carlos Sant'Ana. O mito moderno da natureza intocada. São Paulo, NUPAUB, Universidade de São Paulo, 1994.

FERNANDES, Raimundo Nonato. Da concessão de uso de bens públicos. Revista de Direito Administrativo. Rio de Janeiro, 118, p. 1-11, out./dez., 1974.

FERRAZ, Gildo Correa. Concessão de uso de Terras Públicas como direito real resolúvel. Revista de Direito Agrário. Brasília, 9(8), 2º sem., 1982.

FIGUEIREDO, Lúcia Valle. Curso de Direito Administrativo. São Paulo, Malheiros, 1994.

FUNDAÇÃO VITÓRIA AMAZÔNICA. Os moradores do Parque Nacional do Jaú: censo e levantamento sócio-econômico. Manaus, (Mimeo), 1994.

Plano de manejo do Parque Nacional do Jaú: versão preliminar. Manaus, (Mimeo), novembro de 1996.

GASPARINI, Diogenes. Direito Administrativo. São Paulo, Saraiva, 1993.

GOMES, Manoel Eduardo A. C. \& FELIPE, Luis Daniel. Tutela jurídica sobre as reservas extrativistas. In: O destino da floresta: reservas extrativistas e desenvolvimento sustentável na Amarônia. Rio de Janeiro, Relume-Dumará; Curitiba, Instituto de Estudos Amazônicos e Ambientais, Fudação Konrad Adenauer, 1994.

LARANJEIRA, Raymundo. Propedêutica do Direito Agrário. São Paulo, 2a. ed., 1988.

LIRA, Ricardo Pereira. A concessão do direito real de uso. Revista de Direito Administrativo. Rio de Janeiro, 163, p. 16-57, jan./mar., 1986.

MACHADO, Paulo Affonso Leme. Direito Ambiental Brasileiro. São Paulo, Malheiros, $4^{a}$ ed. revista e ampliada, 1992.

MATTOS NETO, Antonio José de. A posse agraria e suas implicações jurídicas no Brasil. Belém, CEJUP, 1988.

MEIRELLES, Hely Lopes. Direito Administrativo Brasileiro. São Paulo, Malheiros, $18^{\mathrm{a}}$ ed. atualizada por Eurico de Andrade Azevedo, Délcio Balestero Aleixo e José Emmanuel Burle Filho, 1993.

MINISTÉRIO DO MEIO AMBIENTE E DA AMAZÔNIA LEGAL / IBAMA. Roteiro técnico para elaboração/revisão de planos de manejo em áreas protegidas de uso indireto. Brasília, $2^{\mathrm{a}}$ versão, (Mimeo), 1994. 
Unidades de Conservação. Brasília, folder, sem data.

MOREIRA NETO, Diogo de Figueiredo. Curso de Direito Administrativo. Rio de Janeiro, Forense, 1989.

MURRIETA, Julio Ruiz \& RUEDA, Rafael Pinzón. Reservas extrativistas. Glanda, Suiça e Cambridge, Reino Unido, UICN, 1995.

OLIVEIRIA, Regina. Plano de ação emergencial para o Parque Nacional do Jaú: documento de informações básicas. Manaus, (Mimeo), 1994.

RODRIGUES, José Eduardo Ramos. Aspectos jurídicos das unidades de conservação. Revista de Direito Ambiental. São Paulo, Revista dos Tribunais, ano 1, jan./mar., 1996.

SILVA, José Afonso da. Curso de Direito Contitucional Positivo. São Paulo, RTr., 6a ed., 1990.

Direito Ambiental Constitucional. São Paulo, Malheiros Editores, 1994.

SODERO, Fernando Pereira. Atividade agrária. FRANÇA, R. Limongi (org.) Enciclopédia Saraiva do Direito. São Paulo, Saraiva, v. 8, 1978.

SOUSA, João Bosco Medeiros de. Direito Agrário: lições básicas. São Paulo, Saraiva, $3^{a}$ ed., 1994.

SOUZA, Motauri Ciocchetti de. Das unidades de conservação criadas pelo Poder Público: conceito, classificação e possibilidade de cessão de uso a órgão público ou particular. Revista de Direito Ambiental. São Paulo, Revista dos Tribunais, ano 1, jan./mar., 1996.

SOUZA FILHO, Carlos Frederico Marés de. Espaços ambientais protegidos e Unidades de Conservaşão. Curitiba, Universitária Champagnat, 1993.

W.W.F. Subsidios para discussão workshop diretrizes politicas para Unidades de Conservação. Brasília, (Mimeo), novembro/1994. 